\title{
Gestión del conflicto derivado de la oferta de sexo: barrios en disputa
}

\section{Managing the conflict arising from the offer of sex: disputed neighborhoods}

\author{
Martín Boy* \\ Citar este artículo como: Boy, M. (2020). Gestión del conflicto derivado de la oferta de sexo: \\ barrios en disputa. Revista Nodo, 14(28), pp. 74-85.
}

\section{Resumen}

La oferta de sexo en la vía pública suele implicar conflictos urbanos. En este artículo se analizan las características que asumieron las instancias de negociación entre vecinas/os, personas transgénero y funcionarias/os públicas/os relativas a qué debía hacerse con la oferta de sexo en la vía pública.

El conflicto urbano se analiza en este artículo a partir de múltiples dimensiones: tanto las argumentaciones de disputa como el humor, la parodia, las solidaridades y la recreación de la vida cotidiana en torno al espacio público compartido terminan modelando la forma en la que se gestó la solución a un conflicto de corte urbano.

Los resultados plasmados en este artículo parten de una investigación realizada en la ciudad de Montevideo desde una perspectiva cualitativa en la que el propio trabajo de campo me ubicó en una posición inesperada al interior del conflicto. Esto fue posible gracias a una beca posdoctoral otorgada por el Consejo Nacional de Investigaciones Científicas y Técnicas (CONICET).

Palabras clave: conflicto urbano, espacio público, oferta de sexo, transgénero, barrio.

\section{Abstract}

The offer of sex in public space usually involves urban conflicts. In this article, we analyze the characteristics that the negotiation instances between neighbors, trans people, and public authorities assumed about what should be done with the offer of sex in the streets. The urban conflict is analyzed in this article from multiple dimensions: argumentations of dispute, humor, parody, solidarity, and the recreation of everyday life around the shared public space end up modeling how the solution was conceived to a specific urban conflict. The results expressed in this article are based on an

Fecha de recepción: 24 de junio de 2019 • Fecha de aceptación: 25 de noviembre de 2019

\footnotetext{
* Doctor en Ciencias sociales por la Universidad de Buenos Aires. Profesor Universidad de Buenos Aires, Investigador del Instituto de Investigaciones Gino Germani de la Facultad de Ciencias Sociales de la Universidad de Buenos Aires. Profesor de la Universidad Nacional de José C. Paz, Investigador del Instituto de Estudios Sociales en Contextos de Desigualdades de la Universidad Nacional de José C. Paz. Correo electrónico: martinboy.boy@gmail.com
} 
investigation carried out in the city of Montevideo from a qualitative perspective in which the fieldwork itself placed me in an unexpected position, within the conflict. This was possible thanks to a postdoctoral fellowship granted by the Consejo Nacional de Investigaciones Científicas y Técnicas (CONICET).

Keywords: urban conflict, public space, an offer of sex, transgender people, neighborhood.

\section{Introducción}

La oferta de sexo en la vía pública suele motorizar conflictos urbanos entre los grupos que están directa o indirectamente implicados en la actividad. Vecinos/as, quienes ofertan sexo (mujeres cisgénero $\mathrm{y} / \mathrm{o}$ transgénero), funcionarias/os públicas/os en general, fuerzas de seguridad en particular y los medios de comunicación tienden a posicionarse positiva o negativamente frente a esta actividad.

En este artículo se dará cuenta de parte de los resultados que emergen de un trabajo de campo realizado en 2017 en la ciudad de Montevideo en torno a la oferta de sexo en la vía pública en el barrio de Jacinto Vera y Larrañaga, más precisamente sobre el bulevar Artigas y las calles próximas. En este trabajo de campo, se entrevistó a personas transgénero (en adelante trans), vecinas/os y a funcionarias/os públicas/os y, además, se participó activamente de reuniones entre estos tres grupos.

Este trabajo recuperará la perspectiva del conflicto urbano para construir el problema de investigación ya que me permite ver cómo los diferentes actores involucrados construyen alianzas y escisiones para imponer sus propios intereses en un período de tiempo. Esta perspectiva teórica permite dar cuenta del dinamismo de las disputas en y sobre la ciudad y de cómo los diferentes grupos desatan una lucha social para acceder a mejores oportunidades económicas, simbólicas, políticas y de accesibilidad derivados del uso y disposición de ciertos espacios urbanos
(Oszlak, 1991). Dicho lo anterior, el objetivo de este artículo es analizar las formas que adquirió una mesa de negociación mixta realizada en mayo de 2017, conformada por personas trans, vecinas/ os organizadas/os y funcionarias/os públicas/os, en pos de gestionar soluciones al conflicto en torno a la oferta de sexo anclada en el espacio público.

Tal como se ha planteado estos espacios serán pensados como trozos urbanos y no como fragmentos de la ciudad (Boy, 2018). Interpreto que el fragmento representa a una porción urbana que tiene límites o fronteras con respecto a otros fragmentos prolijamente extraídos o recortados. En cambio, la figura de trozo urbano me habilita a concebir al territorio desde lo arrancado, lo desprolijo, lo borroso, lo nómade, lo movible, lo poroso, lo dinámico, lo (i)legítimo. Este movimiento habla de lo inacabado del espacio (Massey, 1994), de la construcción permanente que los diferentes actores ponen en juego a partir de los relatos que emanan. Estos relatos no sólo expresan posiciones que tensionan sino que también dan cuenta de solidaridades y de humoradas que coexisten con el conflicto urbano, incluso en las mesas de negociación donde se dirimen los intereses.

La situación problema de la oferta de sexo en la vía pública será abordada desde una perspectiva del conflicto, a partir de los tironeos por imponer un uso determinado a un espacio público concreto. Sin embargo, quiero dar cuenta de uno de los hallazgos del trabajo de campo realizado. En las reuniones en las que participé, tanto vecinas/ os como trans matizaron los desencuentros con risas, humor y hasta recordaron lazos de solidaridad. Cuando quienes investigamos abordamos conflictos urbanos corremos el riesgo de olvidar los matices, los puntos en común entre los diferentes grupos. Las mesas de negociación, cuando existen, también se ven atravesadas por prácticas amenas que acercan posiciones momentáneamente aunque no disuaden a los diferentes grupos de abandonar sus intereses. En esta dirección tanto las tensiones como los recuerdos divertidos entre los grupos que comparten el barrio producen cons- 
tantemente el espacio público. Sobre estas díadas constitutivas (tensión-solidaridad / enojo-humor / diferencia-empatía) se avanzará en el apartado de los resultados de este artículo. A continuación se señalarán aspectos metodológicos que permitieron llevar a cabo el trabajo de campo durante 2017.

\section{Trama metodológica}

Este artículo responde a un trabajo de investigación cualitativo desarrollado a lo largo del primer semestre de 2017 en la ciudad de Montevideo. La aproximación a la temática fue de tipo cualitativa, con un diseño de investigación flexible. Según Mendizábal (2007), la flexibilidad de este tipo de diseños "se vincula con la actitud abierta, expectante y creativa del investigador cualitativo" ( $p$. 68) a la hora de crear conceptos, hipótesis y teoría a partir de los datos empíricos. Este enfoque, de tipo inductivo, supone que quien investiga esté abierta/o a lo inesperado, a modificar líneas de investigación y el tipo de datos que se buscan, haciendo revisiones constantes de los conceptos utilizados para abordar lo que dicen las personas entrevistadas y lo observado (Mendizábal, 2007). Así, la flexibilidad del diseño implica que los conceptos sean escogidos en la marcha de la investigación y que actúen como guías sin constreñir por anticipado el abordaje de la temática.

Durante el trabajo de campo, se desarrollaron entrevistas en profundidad a los diferentes grupos implicados directa o indirectamente en la oferta de sexo en la vía pública en los barrios de Jacinto Vera y Larrañaga, de la ciudad de Montevideo. Según Taylor y Bogdan (1986) la entrevista en profundidad puede ser definida como aquella que tiene como característica esencial no ser absolutamente cerrada sino estructurada en función de un guión que abre ejes temáticos a examinar, pero que deja abierta la posibilidad de que aparezcan nuevos datos no previstos con anterioridad por quien investiga y que pueden resultar sumamente útiles. Estas entrevistas permitieron reconstruir los pilares que convertía a la oferta de sexo en un conflicto, recuperando tanto las tensiones como las humoradas que fueron parte de la mesa de negociación en la que tuve la oportunidad de participar.

Mi intervención en estos espacios de diálogo fue posible, en primer lugar, gracias a una beca posdoctoral otorgada por el CONICET (Consejo Nacional de Investigaciones Científicas y Técnicas) y, en segundo lugar, fue resultado de una invitación que recibí de las/os funcionarias/os que se desempeñaban en la Secretaría de la Diversidad de la Intendencia de Montevideo, a quienes entrevisté apenas inicié el trabajo de campo. Más allá de que mi presencia respondía a un proceso investigativo, la misma dinámica del trabajo de campo me convirtió en un actor más que propuso dinámicas de encuentro entre los diferentes grupos implicados directa o indirectamente en la oferta de sexo. Por ejemplo, propuse que las reuniones no debían hacerse en las oficinas de la Secretaría ubicadas en el centro de la ciudad sino que era propicio llevarlas a cabo en horarios nocturnos en la zona donde se estaba desarrollando el conflicto.

De esta forma, se organizaron encuentros con las personas trans en una de las plazas aledañas al área donde ofertaban sexo luego de habernos acercado para contarles el proceso de negociación que se estaba iniciando ante las quejas y denuncias de las/os vecinas/os. Se tuvo en cuenta el horario en el que ellas comenzaban a realizar la actividad para no entorpecerlas. Por lo tanto, las reuniones se pautaron alrededor de las $21 \mathrm{hs}$. Con las/os vecinas/os organizadas/os en torno al malestar por la oferta de sexo, se acordó realizar encuentros en la sociedad de fomento donde funcionaba la biblioteca del barrio. De esta forma, no vinieron sólo los dos vecinos que se acercaban usualmente a la oficina en horarios diurnos en representación del resto sino que se acercaron entre 35 y 40 vecinas/ os de todas las edades. Estas reuniones también se llevaron a cabo alrededor de las 19hs, luego de la jornada laboral diurna. En un primer momento, se organizaron reuniones con cada uno de los grupos (trans y vecinas/os) por separado para escuchar 
los intereses y argumentaciones sobre cómo debía utilizarse el barrio y para quién era. En una segunda etapa, se organizaron encuentros mixtos donde también participaron funcionarias/os de otros organismos públicos (Ministerio de Desarrollo Social, Ministerio del Interior, Secretaría de la Diversidad, Ministerio del Interior y Consejeros Vecinales electos).

Este trabajo parte del análisis de los encuentros mixtos para dar cuenta de las negociaciones que incluyeron tanto tensiones y enojos como solidaridades y humor. Personalmente, ser parte de este proceso de investigación-acción me colocó en situaciones inesperadas y me sorprendió: cuando esperaba encuentros altamente tensionantes de acuerdo a mi experiencia en la Ciudad de Buenos Aires por conflictos urbanos similares, me encontraba con grupos que, si bien tenían desencuentros derivados de la oferta de sexo, podían reírse de sus vidas cotidianas nocturnas compartidas en aquellos trozos urbanos. Se conocían, se espiaban, se ayudaban y se molestaban. A continuación, se describirá el escenario barrial donde emergió el conflicto estudiado.

\section{Escenario disputado. Características y sentidos sobre el barrio}

El bulevar General José Artigas es una de las avenidas más transitadas de Montevideo, atraviesa la avenida 18 de julio y termina en el Río de La Plata en el barrio de Punta Carretas. Sobre el bulevar se encuentra la terminal de autobuses Tres Cruces y a 15 minutos en coche de allí en dirección norte se encuentra la zona de oferta callejera de sexo en los barrios Jacinto Vera y Larrañaga, justo antes de llegar al monumento conocido como "Los cuernos de Batlle".

Los barrios mencionados son habitados por clases medias y priman las casas de una planta o dos que tienen un jardín adelante y otro trasero. Las calles transversales y paralelas al bulevar y sus veredas son amplias, poco caminadas, con arboleda y cuentan con dos plazas de tamaño mediano sobre la calle Quijote, paralela al bulevar Artigas. Hoy en día la mayoría de las casas estilo chalet tienen rejas que delimitan un adentro y un afuera y que fueron colocadas según los relatos de las/os vecinas/ os en los últimos años a medida que el conflicto urbano alrededor de la oferta de sexo comenzaba a experimentarse como tal (Figuras 1 y 2). Esto es llamativo, porque la colocación de rejas no se debió principalmente al aumento del delito como en otras ciudades o de la sensación de inseguridad, sino a partir de la premisa de separar un adentro y un afuera, el espacio doméstico del público, el ámbito familiar y la oferta de sexo.

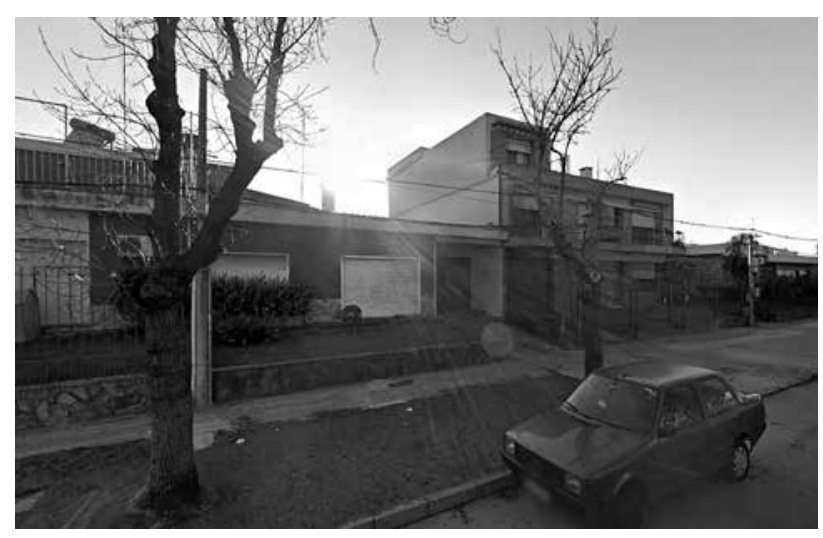

Figura 1. Barrio Larrañaga, Montevideo. Fuente: Google Street View (2019).

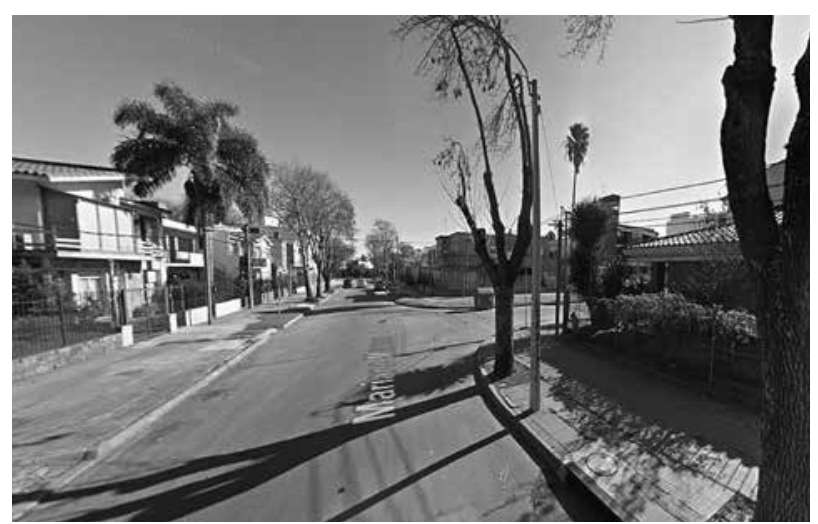

Figura 2. Barrio Larrañaga, Montevideo. Fuente: Google Street View (2019). 
En lo que respecta a la accesibilidad, el barrio cuenta con varias líneas de buses urbanos y quienes tienen automóvil se encuentran a pocos minutos del centro vía el bulevar. La proximidad espacio-temporal con el área central y, a su vez, el mantenimiento de la vida de barrio alejada de los tumultos y embotellamientos de las zonas céntricas son dos valores que las/os vecinas/os organizadas/os en torno al conflicto estudiado rescatan permanentemente.

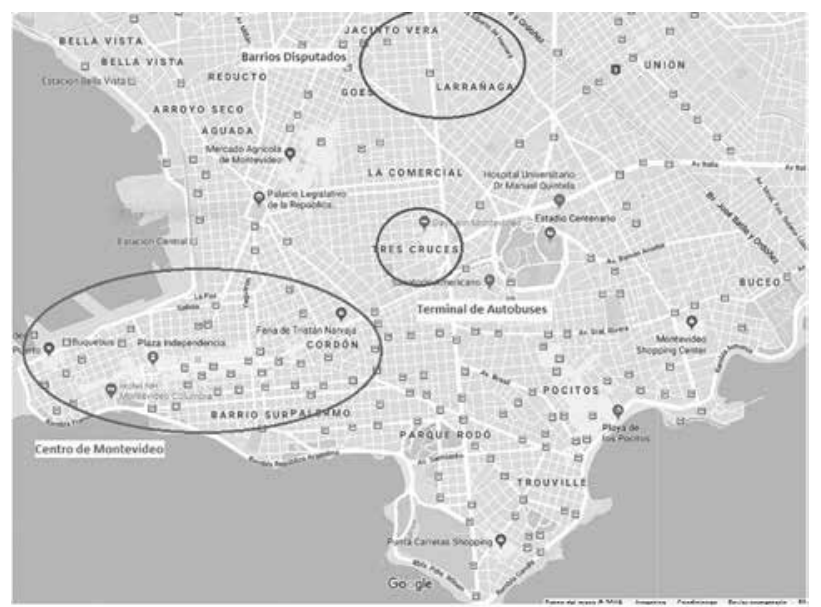

Mapa 1. Áreas de Montevideo de interés. Fuente: elaboración propia a partir de mapas de Google Maps.

En cuanto a la autopercepción, las/os vecinas/os en los relatos que recabé durante mi trabajo de campo representan al barrio en el que viven como propio, tranquilo, libre de embotellamientos, ideal para el desarrollo de la familia y la niñez y lo denominan como el "Carrasquito". Este último término hace referencia a Carrasco, un barrio de élite ubicado en las afueras de Montevideo, a la orilla del río y con playa propia, donde se puede encontrar el monumental "Hotel Casino Carrasco", una frondosa arboleda, una gran cantidad de plazas y parques y casas de estilo inglés de dos plantas. Este barrio se ubica a quince kilómetros del centro montevideano y allí vive la población más rica y tradicional de la ciudad. Por lo tanto, el uso del concepto "Carrasquito" da cuenta de la autopercepción de las/os vecinas/os organizadas/ os del bulevar Artigas, Carrasco actúa para este grupo como un espejo aspiracional.

La inscripción territorial cotidiana de las/os vecinas/os se ancla en el barrio entendiéndolo como un dador de identidad colectiva sobre todo si se trata de aquellos que gozan de prestigio social o cierta reputación. Mayol (1994) sostiene que, desde la perspectiva de las/os habitantes, el barrio es la extensión de la propiedad sobre el espacio público y es el barrio el que los conecta con el resto de la ciudad y el mundo, por ello

Puede considerarse como la privatización progresiva del espacio público. Es un dispositivo práctico cuya función es asegurar una solución de continuidad entre lo más íntimo (el espacio privado de la vivienda) y el más desconocido (el conjunto de la ciudad o hasta, por extensión, el mundo) (...). El barrio es el término medio de una dialéctica existencial (en el nivel personal) y social (en el nivel de grupos de usuarios) entre el dentro y el fuera. Y es en la tensión de estos dos términos, un dentro y un fuera que poco a poco se vuelven la prolongación de un dentro, donde se efectúa la apropiación del espacio. El barrio puede señalarse como una prolongación del habitáculo (...) El barrio es la posibilidad ofrecida a cada uno de inscribir en la ciudad una multitud de trayectorias cuyo núcleo permanece en la esfera de lo privado (p. 10).

El sentimiento de apropiación que las/os vecinas/ os presentan alrededor del espacio público aledaño a sus viviendas puede pensarse como el motor que las/os empuja para organizarse y promover un estilo de vida que las/os identifica colectivamente, borrando las heterogeneidades que puedan existir entre ellas/os para así posicionarse en bloque frente al "foráneo" (Elias, 2003). Estas fronteras simbólicas construidas con el otro que es concebido como extraño y/o peligroso (Amendola, 2000; Bergman y Kessler, 2008) legitima a ciertos grupos por sobre otros. Algunos tendrán más derechos a utilizar y disponer del espacio público que otros, hay intereses superiores y otros secundarios. Cuando Elias (2003) 
trabajó sobre los conflictos derivados de la llegada de nuevas/os habitantes a una localidad de Estados Unidos identificó que la presencia del forastero organizaba y unificaba discursos frente a lo que el autor representaba como una infección anómica. En palabras de dicho autor "la exclusión y la estigmatización de los forasteros por parte del grupo establecido fueron poderosos instrumentos utilizados por este último para preservar su identidad, afirmar su superioridad y mantener a los demás en el lugar que les correspondía" (p. 223).

La presencia de los grupos forasteros representa la aparición de un conflicto de intereses. En esta dirección, un grupo de vecinas/os se organizaron en Montevideo para expulsar a las personas trans de las calles del barrio que les pertenece. El uso de un espacio puede mutar en veinticuatro horas: de día predominan las/os vecinas/os y, por las noches, la calle se transforma en el recurso necesario para las trans para lograr su supervivencia y se produce la llegada de los clientes, de a pie o en coche. De esta forma, el espacio común se encarna, ahora y como nunca, en la calle, aunque con usos diferenciales; la calle sigue siendo el lugar en el cual las diferencias se encuentran, se miden, se solidarizan y se molestan (Boy y Perelman, 2008). Siguiendo esta línea, Carreteiro y Santos (2003) conciben a la calle como un espacio de encuentro de universos complementarios y opuestos y, como tal, la vía pública es vivida como el territorio de la multiplicidad por excelencia. Pero no todos gozan del mismo status y goces de oportunidades.

A continuación, comenzarán a mostrarse los resultados de parte del trabajo de campo realizado, el análisis de las argumentaciones planteadas por los diferentes grupos en las mesas de negociación mixta (trans, vecinas/os y funcionarias/os públicas/os y yo) en las que se dirimieron sus intereses y se plantearon intervenciones concretas en pos de solucionar el conflicto.

\section{Conflicto, argumentaciones de disputa y recursos puestos sobre la mesa}

A partir del año 2004, vecinas/os que residían en los trozos urbanos mencionados comenzaron a presentar denuncias en la Seccional 13 por el incumplimiento de la Ley No. 17.515 de Trabajo Sexual. Esta ley habilitó en julio de 2002 la oferta de sexo en la vía pública bajo ciertas condiciones en todo el territorio uruguayo. En otros países como Argentina donde la oferta de sexo en la vía pública es ilegal, las/os vecinas/os recurren a las fuerzas de seguridad para que multen o arresten a quienes ofertan sexo. En cambio, en países como Uruguay donde esta práctica está legalizada, las/os vecinas/ os recurren no sólo a las Seccionales (comisarías) por incumplimiento de ciertos artículos de la ley sino también a organismos que defienden sus derechos como la Defensoría del Vecino y/o a la Secretaría de Diversidad que tiene un recorrido de trabajo con personas/grupos LGTBI (lesbianas, gays, bisexuales, trans e intersex). En el momento en el que yo me sumo a la gestión del conflicto convocado por la Intendencia, ya se habían presentado cinco denuncias individuales y/o colectivas $y$, además, las/os vecinas/os organizadas/os habían pedido la intervención de la Defensoría del Vecino.

En cuanto al trabajo de campo realizado, la reunión de negociación sobre cómo resolver las situaciones de conflicto en torno a la oferta de sexo en la vía pública se realizó en la biblioteca de la sociedad de fomento emplazada en el mismo trozo urbano donde sucedían los conflictos. La asistencia masiva de ellas/os en una primera reunión, el compromiso de las/os funcionarias/os públicas/os de distintos organismos con el proceso de discusión y la predisposición de las trans a participar dieron lugar a esta instancia de diálogo. Por mi experiencia en el trabajo de campo realizado al caso de la zona roja de Palermo, Ciudad de Buenos Aires, temía que este encuentro fracasara por insultos, atropellos, malos tratos, etcétera. Sin embargo, como suele suceder en la investigación cualitativa, el trabajo de campo me sorprendió. 
Uno de los vecinos representantes comenzó encuadrando la reunión como "una ronda en pos de la convivencia" (Registro de campo, 20/04/2017). Una de las funcionarias organizadoras del encuentro señaló que todas las partes estaban al tanto de por qué existía esta reunión y resaltó que no todas/os las/os vecinas/os pensaban lo mismo y que "no todas las trans piensan y hacen lo mismo". Esta última idea refiere, en parte, a mi insistencia a las/os funcionarias/os que, de acuerdo a mi trabajo de campo, las/os vecinas/ os organizadas/os no representaban al total de la comunidad ya que otras/os argumentaban que no concebían a la oferta de sexo en el barrio como un problema y que, en contraposición a esto, obtenían hasta beneficios de la presencia de personas trans en horarios nocturnos ya que las calles no se encontraban tan solitarias.

La primera de las trans en argumentar comenzó sosteniendo lo siguiente: "Queremos abrir un espacio de escucha, sabemos cuáles son las problemáticas, apostamos al diálogo. (Queremos) Llegar a un punto donde podamos convivir. Avanzar en soluciones. El trabajo sexual es lícito en Uruguay" (Registro de campo, 20/04/2017).

Esta intervención ubicaba a las trans en una posición de reconocer que había conflictos de convivencia anclados en el espacio público que se debían mejorar y que, además, el marco legal uruguayo las habilitaba a ofertar sexo en la vía pública. Desde un plano analítico, ¿Cuándo comienza a haber un conflicto? $¿$ Todas las situaciones con entredichos entre grupos constituyen un conflicto de corte urbano?

Según Melé (2003), hay diferentes formas de concebir a los conflictos sobre el territorio. Algunos creen que se puede hablar de un conflicto a partir del momento en que se expresa en los medios de comunicación como tal; para otros, desde que se vuelve jurídico y, desde una tercera posición, se considera que se puede hablar de conflictos en el caso de cualquier expresión de antagonismos, controversias u oposiciones. En julio de 2016 se había publicado una nota en uno de los diarios de mayor tirada de Uruguay (El País) en el que se señalaba el hartazgo de las/os vecinas/os.

Un concierto de gritos, ruidos de vidrios rotos, botellas tiradas, preservativos usados, bocinazos a cualquier hora, gente que grita. Así es la vida de un grupo de vecinos de la calle Quijote, una de las paralelas a bulevar Artigas en los alrededores de Canal 5. Están preocupados por la forma en que los travestis ${ }^{1}$ ejercen la prostitución en la zona (Elpais.com.uy, 30/07/2016).

Esta nota periodística se publicó y no tuvo un gran impacto mediático. En simultáneo, las/os vecinas/ os sí habían presentado una cantidad de denuncias y solicitado reuniones con la Defensoría del Vecino $^{2}$ y con la Secretaría de Diversidad donde se expresaron sus disconformidades con respecto a lo que sucedía con la oferta de sexo de las personas transgénero en la vía pública de su barrio.

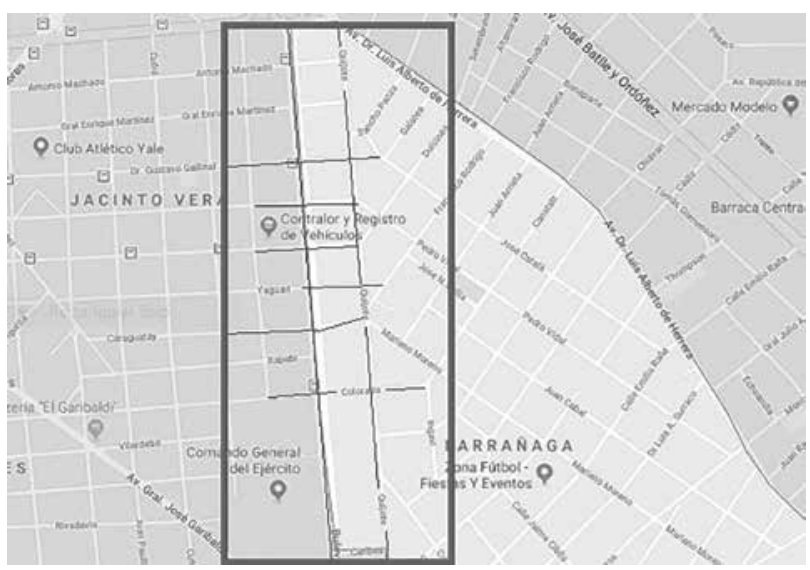

Mapa 2. Calles con oferta de sexo en barrios Larrañaga y Jacinto Vera, Montevideo. Fuente: elaboración propia a partir de Google Maps.

1 Es importante destacar que el término "travesti" en Uruguay tiene una alta carga peyorativa y que, incluso, en esta nota se las representa en masculino.

2 Durante 2017, este organismo cambia de nombre y pasa a llamarse "Defensoría de Vecinas y Vecinos" acorde a una perspectiva inclusiva. Esto motivó la publicación de notas periodísticas con títulos tales como "Defensor del vecino se cambió de sexo" (Elpaís.com.uy, 29/04/2017). En este trabajo se decidió conservar el nombre original ya que el trabajo de campo fue realizado con anterioridad al cambio del nombre de la institución. 
Las argumentaciones presentadas en las denuncias, ya trabajadas anteriormente (Boy, 2018), señalaban la violación a la propiedad privada por parte de quienes ofertaban sexo y de los clientes, los ruidos molestos derivados de los gritos y de los portazos de los coches a altas horas de la noche, el arrojo de preservativos utilizados y de materia fecal en los jardines de las casas, la alteración de la vida social ya que familiares o padres/madres de otras familias no querían asistir a reuniones/ invitaciones por la presencia de personas con torsos desnudos y señalaban que la inocencia de "los chiquilines" del barrio ante estas corporalidades se encontraban en situación de riesgo. Si bien en las reuniones en las que participé estas argumentaciones reflotaban, también sucedieron otras cosas, emergieron dimensiones que, junto a la queja/demanda, conformaron una trama más compleja que dio lugar a los matices. En este contexto de negociación, aparecieron el humor y las risas, la ternura y las solidaridades.

En la reunión mixta que analizaré, se encontraban presentes dos representantes de las/os vecinas/os, cuatro personas trans en representación de quienes ofertaban sexo en la vía pública, funcionarias/os de la Secretaría de la Diversidad y de la Defensoría del Vecino, el Concejal Vecinal y una integrante de la Junta Departamental de Montevideo electas/os, una pasante de trabajo social, la encargada de la biblioteca de la sociedad de fomento y yo, presentado usualmente como "el investigador con expertise" llegado de Buenos Aires. En cuanto a las situaciones conflictivas, los vecinos representantes manifestaron su preocupación porque varias/os de las/os vecinas/os representada/os se mostraban demasiado alteradas/os ante el cúmulo de problemas cotidianos sumados en el tiempo. Uno de ellos manifestó lo siguiente:

Esto no es un tema de ahora. Queremos abrir los brazos, esto no es un caso de discriminación. Lo mejor es sentarnos acá y llegar a un camino de diálogo. Tenemos miedo que se pase un límite (Registro de campo, 20/04/2017).
Las trans manifestaron que en alguna ocasión habían sido heridas con bombas brasileras ${ }^{3}$ arrojadas por algún/a vecino/a debido a su presencia. Sin embargo, reconocieron que el grupo de las trans más jóvenes eran las que ocasionaban mayores problemas y que las tenían ubicadas como el grupo que "paraba" en una esquina determinada. Con respecto a esto, una de ellas sostuvo lo siguiente:

Somos una población conflictiva, pero no somos extraterrestres. No vengo a acá a perder dinero que después lo tengo que ganar en el frío del invierno. Necesitamos que vengan con la posta y nos comuniquen los problemas concretos en esquinas concretas (Luisa, registro de campo, 20/04/2017).

El pedido de Luisa estaba relacionado con la necesidad de identificar prácticas concretas para que ellas pudieran hablar con las trans "problemáticas", "las jóvenes", que solían ser las más disruptivas. Geraldine, otra de las trans presentes, manifestó que "a las nuevas hay que explicarles. Te dicen que hacen lo que hacen con los vecinos que les dicen 'maricón". Es decir que identificaba estas prácticas como respuesta a agravios de las/os vecinas/os. Finalmente, Jesica manifestó que debía llegarse a un arreglo por medio de la palabra con la siguiente idea conciliadora: "(Hay que) buscar maneras de diálogo, yo sé que es cansador”. De esta forma, las trans reunidas reconocían que las/os vecinas/ os tenían argumentos válidos e identificaban a un subgrupo de trans como las principales responsables. Ellas se comprometían a convencerlas para bajar la conflictividad. A su vez, los dos vecinos presentes, se comprometieron a charlar con aquellas/os que se encontraban al borde de la saturación para bajar también la conflictividad. De esta forma, las dos partes parecían llegar a una especie de arreglo que posibilitaba negociar la coexistencia de las dos partes en un mismo espacio público. Es

3 La bomba brasilera es un artefacto de pirotecnia que, si no se usa correctamente, puede generar lesiones. En aquella oportunidad, un vecino desde su casa le arrojó una bomba brasilera a una trans y le provocó la explosión de una de sus prótesis de silicona. 
decir, los dos vecinos presentes no expusieron el interés que habían manifestado en otras reuniones donde las trans no estaban presentes: que ellas se fueran del barrio. Las posiciones presentadas por las partes y los deseos acallados, dieron el pie para que sucedieran otras situaciones.

En el transcurso de la reunión de negociación, la charla por momentos recuperaba aspectos de la vida cotidiana en el barrio a través de recuerdos. En esas anécdotas compartidas emergió el humor, las risas y sentimientos que desde la investigación sobre conflictos urbanos no solemos comprender como parte de las situaciones de disputa. En esta dirección, uno de los vecinos recordó a Geraldine y le dijo:

'Yo te conozco, me acuerdo de vos. Una noche, a eso de las dos de la mañana, estabas paseando con una bicicleta, con los brazos abiertos, por las calles, gritando como una loca`. En ese momento, todas las partes presentes nos reímos de la situación. Ella se lo negó. Y él le insistió y emuló el ruido de los gritos. En ese instante, ella se sonrojó, toda su cara se puso roja, miró para abajo y lo admitió: 'Bueno, es verdad. Lo que pasó fue que una compañera me prestó su bicicleta y yo no andaba desde que tenía diez años. Fue como juguete nuevo para una chiquilina' (Vecino y trans, registro de campo, 20/-4/2017).

Las risas que despertó la reactualización del recuerdo, comenzó a tamizar toda la reunión. La mesa de negociación devino en un encuentro teñido de escenas cotidianas compartidas. De esta forma, aquello que estaba planteado en términos de conflicto comenzaba a mostrar otras aristas para mí sorprendentes, inesperadas. Cuando uno de los vecinos retomó la senda de los reclamos y habló de los cuerpos desnudos y de los gritos, tres de las cuatro trans presentes volvieron a retomar el camino del humor llevando la situación hasta el ridículo:

Las lolas ${ }^{4}$ nuestras te saludan antes que nosotras. El vecino se enoja porque hay alguien que grita

$4 \quad$ El término "lola" remite a seno. desde los autos (Geraldine, registro de campo, 20/04/2017).

No es mi culpa si gritan, yo no soy inspectora de tránsito. Nos increpan por los ruidos de las puertas de los autos, eso no es un ruido molesto (...) no nos podemos hacer cargo de las bocinas y gritos. Es como que me tenga que hacer cargo de una ambulancia (por el ruido que genera). Tenemos que buscar soluciones coherentes, no puedo evitar los gritos de clientes, los ruidos de las puertas, etc. Sí podemos laburar (negociar) lo de los jardines (Luisa, registro de campo, 20/04/2017).

Por un lado Geraldine, alta y robusta, parodió los dichos del vecino apelando a las corporalidades usualmente voluptuosas e irresistibles, para muchos, de las trans; por otro lado, Luisa continuó en esa dirección pero supo también aceptar como parte de la negociación que había algunos puntos de la queja que eran legítimos y que ellas podían comprometerse a entablar el diálogo con las trans que se entrometían en las propiedades para defecar o para mantener relaciones sexuales. Ante estas situaciones me pregunté tiempo después con qué finalidad las trans incorporaban estos comentarios: ¿Había una finalidad explícita? ¿Qué resonancias tuvieron? ¿Cómo podemos problematizar teóricamente el uso del humor en la gestión de los conflictos?

La antropóloga Cutuli (2015) en su tesis de doctorado problematiza cómo un grupo de travestis gesta y sostiene una cooperativa textil en Buenos Aires. La autora identifica cómo la lógica de la parodia es parte del funcionamiento del emprendimiento productivo y señala que se constituye como "una manera recurrente de lidiar con situaciones problemáticas o suavizar conflictos" (p. 133). Retomando a Scott, Cutuli (2015) entiende a la lógica de la parodia como una estrategia de resistencia y confrontación en un "discurso oculto" que encuentran los grupos subalternos para contrarrestar el peso de los condicionamientos, prácticas o posicionamientos ideológicos (p. 163). Siguiendo esta línea, con cada intervención de las trans en la mesa 
de negociación que despertaba risas, humoradas y ternura, pude identificar cómo los dos vecinos representantes del barrio perdían la posición de demandantes. De esta forma, las intervenciones de ellas terminaban descontracturando el encuentro y sacándolos de la posición de enojo legítimo.

Las risas y los chistes dieron lugar a otro tipo de diálogos, emergieron recuerdos de la vida cotidiana compartida en formato de anécdotas que recreaban otra trama de interacciones que se vinculaban más a las solidaridades que a las tensiones propias de un conflicto. Tal como se trabajó en otra oportunidad (Boy, 2014), el énfasis puesto en lo que se tiene en común recuperado como una red de reciprocidades necesaria para vivir mejor tiene como efecto la aparición de un Otro que hermana, que acerca. Así, emerge la figura del delincuente que, al decir de Hall (2003), se conforma como "un afuera constitutivo" (p. 18).

En esta dirección, Luisa y sus compañeras señalaron que más allá de las situaciones conflictivas también existían lazos de solidaridad entre las/os vecinas/os y ellas.

Yo sé que los vecinos de mi esquina no se quejan de mí, el vecino que pasea la perra vieja me ayudó ante casos de inseguridad y yo les ayudo con otras cosas... Somos independientes, no hay quien nos cuide, no hay ventas de drogas (Luisa, registro de campo, 20/04/2017).

Usted es el vecino del auto blanco... ah, usted es el que me alcanzó el agua, el que pasea el perrito(Jesica, registro de campo, 20/04/2017).

El que robó las dos sillas me dio una y yo le pegué. Yo corrí a gente que se mete en el jardín (Geraldine, registro de campo, 20/04/2017).

Por su parte, Jesica contó la anécdota en la que impidió que robaran en un coche. El vecino había dejado olvidadas las llaves puestas. Lo hizo a pesar de que el día anterior le habían dicho de todo: 'puto de mierda' le habían gritado porque estaba desnuda (Jesica, registro de campo, 20/04/2017).
Tal como puede observarse, los dichos de las trans en la reunión recuperan la figura del delincuente como un actor ajeno a ellas y a las/os vecinas/ os que cumple la función de representar el mal mayor. El uso estratégico de esta figura deslegitimaba por momentos la importancia de lo que se estaba discutiendo, intentaba acercar posiciones y depositaba el peligro y el delito en otro grupo, ajeno a las dos partes que estaban negociando.

Ante un último intento de uno de los vecinos de relacionarlas con el consumo de drogas y con la llegada de sujetos peligrosos al barrio, Luisa le contestó:

Los chicos que se drogan en Pedernal y bulevar (intersección de dos calles) son vecinos del barrio (...), sus hijos ¿Ustedes creen que nuestros clientes que vienen a pie bajan del Cerro $^{5}$ ? No, si vienen a pie es porque son los maridos de las casas de familia de este barrio que vienen a pedir nuestros servicios (Luisa, registro de campo, 20/04/2017).

De esta forma, Luisa desplegó otro tipo de respuesta que se alejaba esta vez del humor e intentaba contraatacar los embates del vecino. Así quedó claro que la mesa de negociación viraba entre los reclamos, el humor, la vida cotidiana compartida y las respuestas que actuaban como contraofensivas.

La mesa de negociación culminó con la lectura de ocho puntos. Cinco de estos apuntaban a aumentar el control sobre la oferta de sexo y sobre quienes lo ejercían directamente (que las/os vecinas/os pudieran exigir libreta sanitaria a las trans, por ejemplo) o indirectamente (instalación de más luminaria para ahuyentar a clientes, por ejemplo). Los cinco fueron rechazados. Los tres puntos aceptados por las dos partes tendieron a mejorar las condiciones de trabajo sexual para

5 El Cerro es uno de los barrios históricos de Montevideo que hoy se encuentra habitado por sectores populares. Es reconocido por su inseguridad y marginalidad. Se encuentra alejado del barrio en disputa. 
ellas: instalación de cestos especiales para arrojar los preservativos usados, colocación de baños químicos en las dos plazas de la zona para que ellas pudieran hacer sus necesidades fisiológicas y garitas que las cubrieran de la lluvia, sobre todo para las noches de invierno. Las/os funcionarias/ os públicas/os presentes sintieron que la reunión había sido un éxito y se comprometieron a realizar las tratativas para que la Intendencia avanzara con las instalaciones negociadas. Una de las funcionarias señaló a modo de cierre: "Hay acuerdos: ni forros ${ }^{6}$, ni tirar baldazos, ni que griten los vecinos para que los clientes se espanten" (Silvina, registro de campo, 20/04/2017).

El 25 de abril, cinco días más tarde, los dos vecinos representantes enviaron un correo electrónico en el que manifestaban que lo acordado en la reunión no representaba los intereses del vecindario y que daban de baja unilateralmente lo convenido. Y solicitaron una reunión con las autoridades sin la presencia de ellas. Y se la concedieron. Allí, mencionaron que las/os vecinas/os querían que ellas no estén en el barrio y que su presencia alteraba el valor inmobiliario de sus viviendas. Es decir, manifestaron todo lo que habían presentado en las denuncias y que no se animaron a explicitar en la reunión frente a las trans.

\section{Reflexiones de cierre}

La oferta de sexo en la vía pública suele ocasionar conflictos urbanos entre los diferentes grupos que directa o indirectamente se encuentran involucrados. La perspectiva del conflicto permite problematizar a la ciudad desde el movimiento, desde el tironeo, desde lo nómade. Cada uno de los grupos promoverá sus propios intereses y tratará de permanecer en el espacio público disputado. En esta oportunidad, analicé cómo en un país como Uruguay donde la oferta de sexo en la vía pública es legal desde 2002 no deja de representar un problema para parte del vecindario que motoriza una organización colectiva y el armado de mesas de negociación.

La existencia de las reuniones entre vecinas/os organizadas/os, trans y funcionarias/os públicas/ os puede ser leída como el reconocimiento de que la oferta de sexo implica una situación de conflicto que debe ser solucionada. La identificación de este punto de partida es importante ya que las/os vecinas/os terminan reconociendo a las trans como un interlocutor válido para negociar. En muchas otras situaciones, los grupos no admiten el conflicto y activan otras dinámicas de lucha social para imponerse.

En este artículo fue central reconstruir las características que asumieron estas reuniones mixtas intentando incorporar matices novedosos, al menos para mí, a las aproximaciones analíticas que solemos construir quienes realizamos investigaciones sobre los conflictos urbanos. En general, tendemos a pensar las disputas urbanas desde los posicionamientos estratégicos, las argumentaciones y las alianzas de los grupos involucrados dejando de lado otros ingredientes que pueden ser centrales en la resolución de los conflictos urbanos. En este caso, el humor, la parodia, la ternura y el contraataque protagonizados por las trans fueron recursos puestos en juego en la mesa de negociación para equilibrar la balanza a su favor. De esta forma, las risas, sonrojarse, la recreación de anécdotas nocturnas compartidas y la recuperación de la figura del verdadero sujeto peligroso, encarnado en el delincuente, fueron movimientos que repercutieron en los puntos consensuados de cara a encontrar soluciones de convivencia. Estos recursos lograron que los vecinos que actuaban como representantes, descolocados, negociaran alejándose de sus representadas/os, casi sin darse cuenta. Días después, en cuanto la información sobre lo negociado se diseminó por el barrio y el descontento se instaló, las/os vecinas/os decidieron deshacer lo convenido.

6 El término "forro" remite a preservativo. 


\section{Referencias bibliográficas}

Amendola, G. (2000). La Ciudad Postmoderna. Magia y miedo de la metrópolis contemporánea. Madrid, España: Celeste Ediciones.

Bergman, M. y Kessler, G. (2008). Vulnerabilidad al delito y sentimiento de inseguridad en Buenos Aires: Determinantes y consecuencias. Desarrollo Económico - Revista de Ciencias Sociales, 190-191(48), pp. 209-234.

Boy, M. y Perelman, M. (2008). Los Sin Techo de Buenos Aires. Revista Ciudades. Las múltiples manifestaciones de la pobreza, 78, pp. 2-7.

Boy, M. (2014). Conflictos, solidaridades y miradas en torno a la situación de calle. Revista Estudios Sociológicos. 32(94), pp. 45-71.

Boy, M. (2018). Vecinos/as vs. trans: disputas en torno a la oferta de sexo en el Boulevard Artigas. Montevideo, 2005-2017. IX Jornadas de Investigación en Antropología Social "Santiago Wallace". Facultad de Filosof ía y Letras, Universidad de Buenos Aires.

Carreteiro, T. y Santos, P. (2003). La calle: espacios múltiples en Brasil. Revista Pobreza y Desigualdad. Proposiciones, 34.

Cutuli, S. (2015). Entre el escándalo y el trabajo digno. Etnografía de la trama social del activismo travesti en Buenos Aires (tesis doctoral). Universidad de Buenos Aires, Buenos Aires, Argentina:

Elias, N. (2003). Ensayo acerca de las relaciones entre establecidos y forasteros. Revista REIS. Revista Española de Investigaciones Sociológicas, 104, pp. 219-251.
El Pais Uruguay (29 de abril de 2017). Defensor del vecino se cambió de sexo. Diario El País. Disponible en: [https://www.elpais.com.uy/ informacion/defensor-vecino-cambio-sexo. $\mathrm{html} /]$.

El Pais Uruguay (30 de julio de 2016). Difícil convivencia entre los vecinos y travestis. Denuncian sexo, alcohol y drogas a la vista en plena calle. Diario El País. Disponible en: [https://www. elpais.com.uy/informacion/dificil-convivenciavecinos-travestis.html/].

Hall, S. (2003). Introducción: ¿Quién necesita 'identidad'?. En S. Hall Y Y P. Dugay (Eds.) Cuestiones de identidad cultural. Buenos Aires, Argentina: Amorrortu.

Massey, D. (1994) Space, Place, and Gender. Minneapolis: University of Minnesota Press

Mayol, P. (1994). El barrio. En: De Certeau, M., Giard, L. y Mayol, P. (Eds.). La invención de lo cotidiano, T. 2. Habitar, cocinar. Ciudad de México: Universidad Iberoamericana.

Melé, P. (2003). Introducción: Conflictos, territorios y acción pública, Conflits et territories, 224.

Mendizábal, N. (2007). Los componentes del diseño flexible en la investigación cualitativa. En: Vasilachis, I. (Ed.). Estrategias de investigación cualitativa. Buenos Aires, Argentina: Gedisa.

Oszlak, O. (1991). Merecer la Ciudad. Los pobres $y$ el derecho al espacio urbano. Buenos Aires, Argentina: Humanitas-CEDES.

Taylor, S. y Bogdan, R. (1986). Introducción a los métodos cualitativos de investigación. Buenos Aires, Argentina: Paidós. 